Tegenaria medicinalis Hentz is near Coelotes atropos, possibly the same species.

Micrommata canadensis Hentz is represented by the common Ocyale mirabilis.

Pylarus bicolor Hentz belongs to the genus Ariadne, and is very near $A$. insidiatrix.

Leipzig, Dec. 16, 1875.

J. H. Emerton.

\title{
Arctic Lepidoptera in the White Mountains.
}

Mr. Roland Thaxter sends me a male specimen, taken by Mr. B. P. Mann, above the tree-line, on Mount Washington, which seems to be the first indication of the probable occurrence of Laria Rossii Curtis on the mountains, and still further to illustrate the relations between the Arctic and Mount Washington faunæ. The specimen is a male, smaller than Curtis' figure, with the dark band on the secondaries so broadened and diffused as to leave but a discal yellowish patch. The markings on the fore wings seem quite similar, and, in the absence of a larger series of specimens, the more closely scaled and rather darker Mount Washington specimen should not be held to indicate a distinct species. It appears that arctic species are subject, as a rule, to unusual variation. My specimens of Pachnobia carnea from Labrador strongly vary in depth of color and distinctness of marking; a specimen, undoubtedly of this species, sent me by Mr. Morrison, from Mount Washington, is very pale. We shall probably find, when more material is collected together, that we have, besides Anarta melanopa, Agrotis islandica, and Pachnobia carnea, also the Bombycid Laria Rossii to add to our list of Arctic Lepidoptera found in the Mountains of New Hampshire. A. R. Grote.

\section{Chrysalis with attached Larval Head.}

Mr. Roland Thaxter brought me, Sept. 27th, 1875, the living chrysalis of Euphoeades Troilus, with the head of the caterpillar still remaining upon it. The head is split, as ordinarily when cast for the last time, and the two hemispheres hug the 

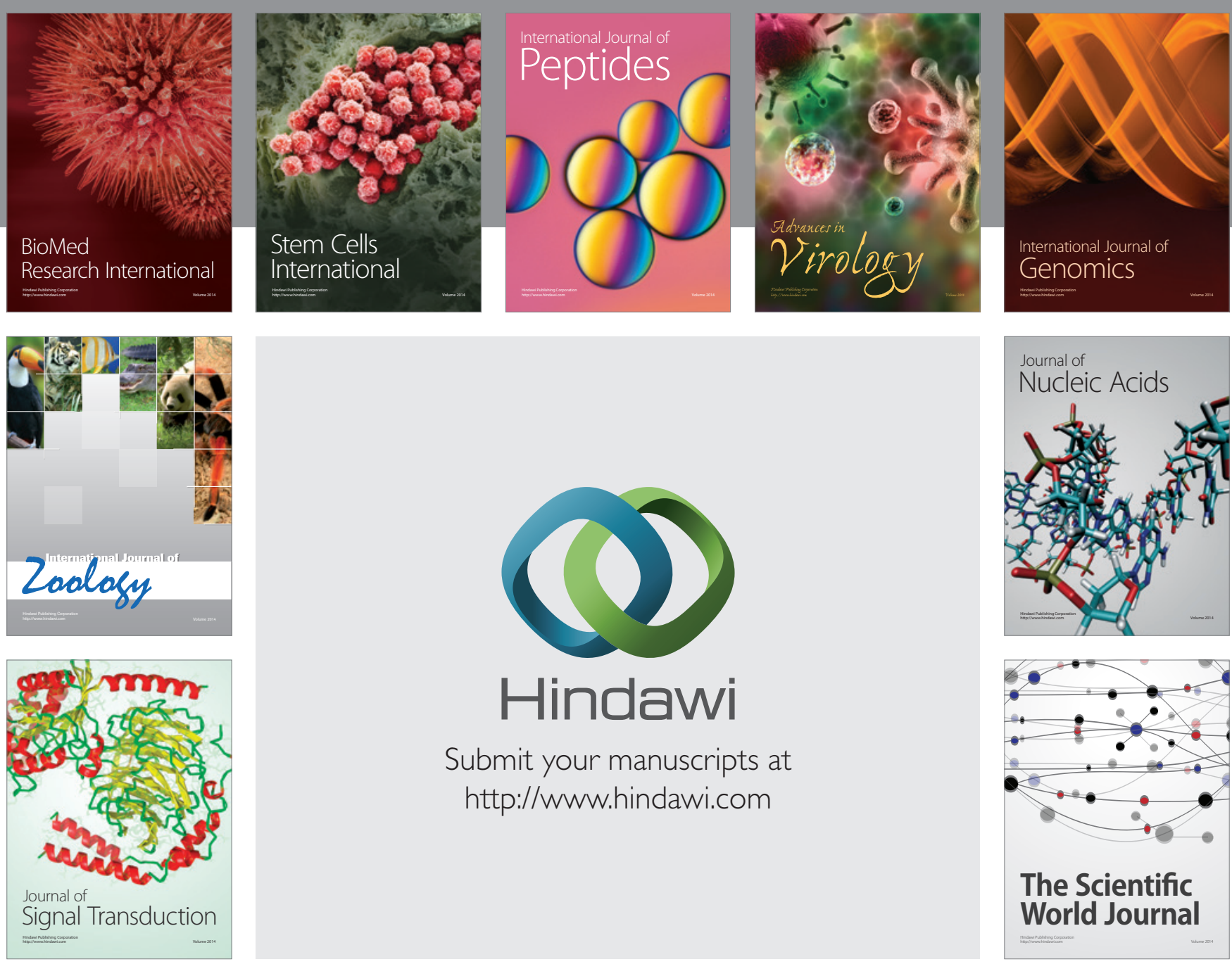

Submit your manuscripts at

http://www.hindawi.com
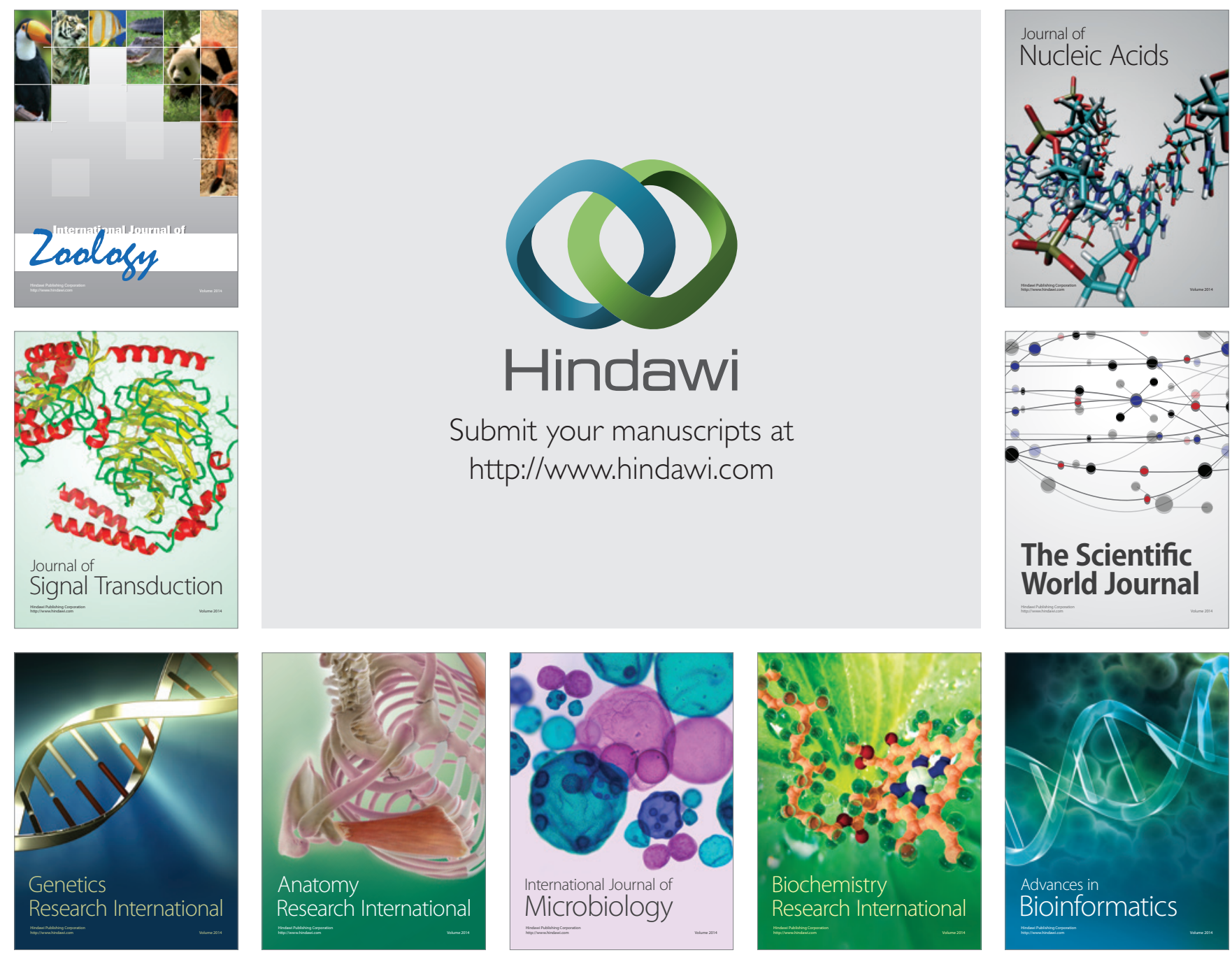

The Scientific World Journal
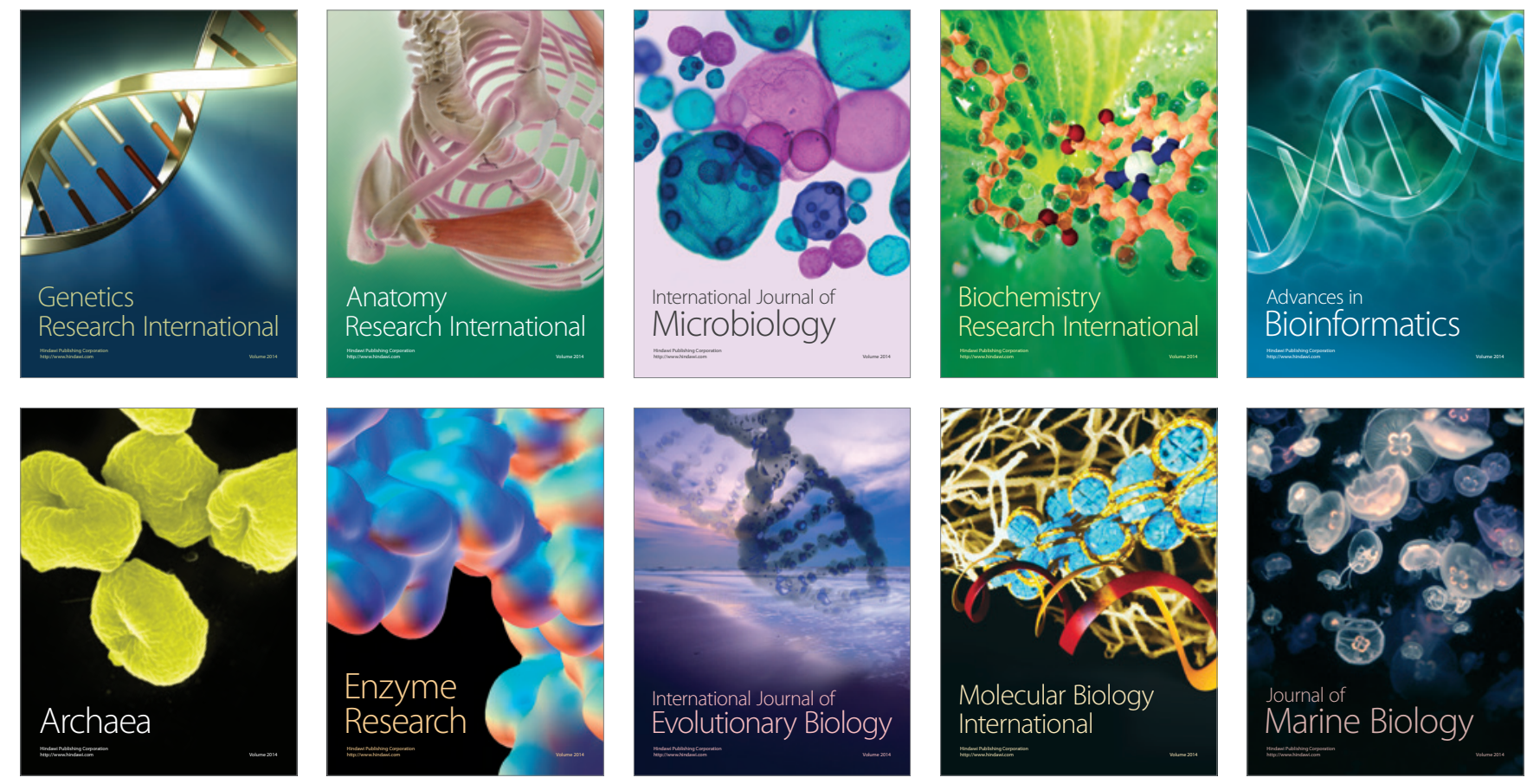